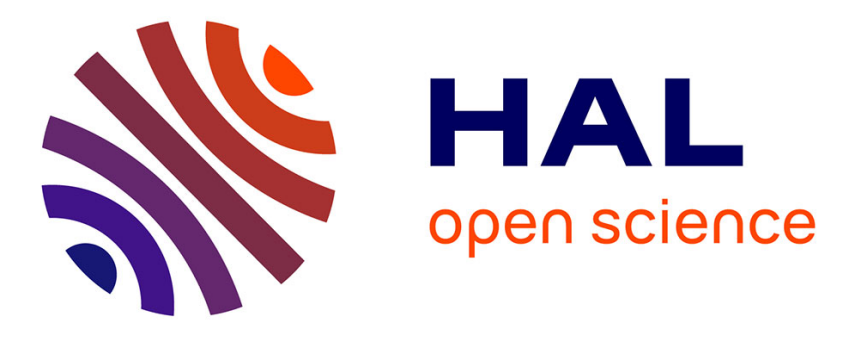

\title{
On the Stabilizing Virtues of Imperfect Competition
} Thomas Seegmuller

\section{To cite this version:}

Thomas Seegmuller. On the Stabilizing Virtues of Imperfect Competition. International Journal of Economic Theory, 2005, 1 (4), pp.313-323. 10.1111/j.1742-7363.2005.00019.x . halshs-00194173

\section{HAL Id: halshs-00194173 https://shs.hal.science/halshs-00194173}

Submitted on 5 Dec 2007

HAL is a multi-disciplinary open access archive for the deposit and dissemination of scientific research documents, whether they are published or not. The documents may come from teaching and research institutions in France or abroad, or from public or private research centers.
L'archive ouverte pluridisciplinaire HAL, est destinée au dépôt et à la diffusion de documents scientifiques de niveau recherche, publiés ou non, émanant des établissements d'enseignement et de recherche français ou étrangers, des laboratoires publics ou privés. 


\title{
On the Stabilizing Virtues of Imperfect Competition ${ }^{1}$
}

\author{
Thomas Seegmuller \\ CNRS and EUREQua, \\ 106-112 Boulevard de l'Hôpital 75647 Paris Cedex 13 France \\ tel: (33) 144078199 \\ fax: (33) 144078231 \\ e-mail: seegmu@univ-paris1.fr
}

\footnotetext{
${ }^{1}$ We would like to thank an anonymous referee for helpful remarks that have improved the paper. We also thank Teresa Lloyd-Braga for comments and suggestions on a previous version of this paper. All remaining errors are of our own responsibility.
} 


\begin{abstract}
We analyze the stabilizing role of imperfect competition on fluctuations due to indeterminacy and endogenous cycles. In this paper, imperfect competition is a source of monopoly profits, because of producer market power. Considering an overlapping generations model with capital accumulation and elastic labor supply, we show that under imperfect competition, the emergence of endogenous fluctuations requires a weaker substitution between production factors than under perfect competition. In this sense, imperfect competition stabilizes fluctuations. However, we find an opposite conclusion concerning the elasticity of labor supply. Indeed, endogenous fluctuations are compatible with a less elastic labor supply under imperfect competition.
\end{abstract}

JEL classification: D43, E32.

Keywords: Indeterminacy, endogenous fluctuations, imperfect competition, monopoly profits, mark-up. 


\section{Introduction}

Imperfect competition has notably been introduced in macroeconomic dynamic models to study the influence of internal increasing returns to scale (Benhabib and Farmer (1994), Cazzavillan, Lloyd-Braga and Pintus (1998), Lloyd-Braga (1995)) and mark-up variability (d'Aspremont, Dos Santos Ferreira and Gérard-Varet (1995), Gali (1994), Weder (2000), Woodford (1991)) on the emergence of endogenous fluctuations. These works conclude that imperfect competition promotes the occurrence of local indeterminacy and endogenous cycles. ${ }^{2}$ A similar conclusion has recently been obtained by Jacobsen (2000) even if, in his framework, imperfect competition affects dynamics through a different mechanism than the two previous ones. Indeed, he has studied the role of the level of mark-up and monopoly profits on the occurrence of endogenous cycles. ${ }^{3}$ Introducing monopolistic competition in a monetary overlapping generations economy where firms have a constant returns to scale technology, he shows that contrary to a perfectly competitive economy (Grandmont (1985)), endogenous fluctuations are compatible with an increasing labor supply if the mark-up is strong enough. It comes from an additional wealth effect due to the existence of monopoly profits. However, Jacobsen (2000) does not consider capital accumulation and so profits are constant at equilibrium.

In this paper, we study the influence of monopoly profits on the emergence of endogenous fluctuations introducing monopolistic competition (Dixit and Stiglitz (1977)) in an overlapping generations economy with elastic labor supply and productive capital. In contrast to Jacobsen (2000), monopoly profits are not constant at equilibrium. ${ }^{4}$ In this framework, we discuss the stabilizing dynamic properties of imperfect competition. We are able to establish our results not only in function of the labor supply elasticity, but also in function of the substitution between capital and labor.

Studying local dynamics, we show that the emergence of endogenous fluctuations requires a weaker substitution between capital and labor than in a perfectly competitive economy (Reichlin (1986)). Indeed, the range for indeterminacy and endogenous cycles of the substitution between capital and labor decreases and becomes closer to zero when mark-up and monopoly

\footnotetext{
${ }^{2}$ For a survey, see Benhabib and Farmer (1999) or Silvestre (1995).

${ }^{3}$ In a related model, Dos Santos Ferreira and Lloyd-Braga (2002) show that market power and monopoly profits can be a source of endogenous growth in overlapping generations economies.

${ }^{4}$ Jacobsen (2000) also introduces imperfect competition on the labor market in order to generate unemployment. For simplification, we rather assume that the labor market is perfectly competitive.
} 
profits increase. In other words, concerning the substitution between capital and labor, endogenous fluctuations can occur under a more restrictive condition than under perfect competition. Moreover, this condition is not verified by empirical studies. ${ }^{5}$ In this sense, imperfect competition stabilizes fluctuations. On the contrary, a higher level of mark-up increases the range of elasticities of labor supply compatible with indeterminacy. Under imperfect competition, endogenous fluctuations can occur if the labor supply is less elastic than under perfect competition, which is in accordance with the usual idea that labor supply is not too elastic with respect to the real wage. Hence, from this point of view, imperfect competition rather promotes endogenous fluctuations.

The rest of the paper is organized as follows. In section 2, we present the model. In section 3, we study local dynamics. We conclude in section 4 . Some details are given in the Appendix

\section{The Model}

We consider an overlapping generations economy with discrete time, $t=$ $1,2, \ldots, \infty$. At each period, a continuum of consumers, living two periods, is born and has a size normalized to one. When young, consumers supply labor $l_{t}$, save through the purchase of productive capital $k_{t}$ and consume only when old. Capital totally depreciates after one period of use. Moreover, consumer preferences are separable between consumption and leisure and can be written:

$$
B U\left(C_{t+1} / B\right)-V\left(l_{t}\right)
$$

where $B>0$ is a scaling parameter, $C_{t+1}$ represents the consumption and is defined by the aggregate of varieties:

$$
C_{t+1}=\left(\int_{0}^{1} c_{t+1}(i)^{1 / \mu} d i\right)^{\mu}
$$

where $\mu>1 .^{6}$ The capital is defined by the same aggregate of varieties. On the utility function, we further assume:

\footnotetext{
${ }^{5}$ See among others Duffy and Papageorgiou (2000).

${ }^{6}$ Using this specification, one can notice that $\mu /(\mu-1)>0$ represents the elasticity of substitution between the different varieties of good. This elasticity decreases with respect to $\mu$ and tends to $+\infty$ when $\mu$ tends to 1 . In this last case, the different varieties become perfect substitutes.
} 
Assumption 1 The functions $U(x)$ and $V(l)$ are continuous for all $x \geq 0$ and $0 \leq l \leq \bar{l}$, where the labor endowment $\bar{l}>1$ may be finite or infinite. They have continuous derivatives of every required order for $x>0,0<l<\bar{l}$, with $U^{\prime}(x)>0, U^{\prime \prime}(x) \leq 0, V^{\prime}(l)>0$ and $V^{\prime \prime}(l) \geq 0$. Moreover, $\epsilon_{u}(x) \equiv$ $-x U^{\prime \prime}(x) / U^{\prime}(x)<1$ and $\lim _{l \rightarrow l} V^{\prime}(l)=+\infty$.

Consumers do not only earn their labor income but also receive profits distributed by firms when young. Hence, noting $\omega_{t}$ the real wage, $\rho_{t+1}$ the real interest factor and $\pi_{t}$ the real profits at period $t$, the budget constraints of the consumer are defined by:

$$
\begin{aligned}
& k_{t}=\omega_{t} l_{t}+\pi_{t} \\
& C_{t+1}=\rho_{t+1} k_{t}
\end{aligned}
$$

Taken into account that consumption is defined by (2), each consumer maximizes his utility function (1) under the two budget constraints (3) and (4). ${ }^{7}$ He can solve this problem in two steps. First, he chooses his consumption of each variety of final good taken as given all other variables, like labor, capital and aggregate consumption ${ }^{8}$ :

$$
c_{t+1}(i)=\left(\frac{p_{t+1}(i)}{P_{t+1}}\right)^{-\frac{\mu}{\mu-1}} \frac{R_{t+1}}{P_{t+1}}
$$

where $R_{t+1}=P_{t+1} C_{t+1}=\int_{0}^{1} p_{t+1}(i) c_{t+1}(i) d i, p_{t+1}(i)$ is the price of variety $i$ and $P_{t+1}=\left(\int_{0}^{1} p_{t+1}^{\frac{1}{1-\mu}}(i) d i\right)^{1-\mu}$ the aggregate price. Secondly, he determines

${ }^{7}$ Note at this stage that the overlapping generations model that we develop can also be interpreted as a discrete time model with a representative infinitely lived agent who maximizes the utility:

$$
\sum_{t=1}^{+\infty} \beta^{t-1}\left[B U\left(C_{t} / B\right)-\beta V\left(l_{t}\right)\right]
$$

where $\beta \in(0,1)$ represents the discount factor and $C_{t}$ the same aggregate of varieties as above, and who faces the two constraints:

$$
\begin{aligned}
& C_{t}+k_{t}=\rho_{t} k_{t-1}+\omega_{t} l_{t}+\pi_{t} \\
& C_{t} \leq \rho_{t} k_{t-1}
\end{aligned}
$$

If the last inequality, which can be interpreted as a finance constraint, is binding at equilibrium, one obtains exactly the same dynamics than in the overlapping generations model that we present in this paper. For more details, see Seegmuller (2005).

${ }^{8}$ Some details are given in the Appendix 
his intertemporal choice between future consumption and labor:

$$
U^{\prime}\left(\rho_{t+1} k_{t} / B\right) \rho_{t+1} \omega_{t}=V^{\prime}\left(l_{t}\right)
$$

This equation defines the labor supply. Indeed, substituting (3) into (6), one obtains:

$$
U^{\prime}\left(\rho_{t+1}\left(\omega_{t} l_{t}+\pi_{t}\right) / B\right) \rho_{t+1} \omega_{t}=V^{\prime}\left(l_{t}\right)
$$

This expression implicitly determines the labor supply as a function of real wage, real profits and future real interest rate. Under Assumption 1, the labor supply increases with respect to the real wage. Indeed, differentiating equation (7), the elasticity $\epsilon_{l_{t}^{s}} \equiv \frac{\partial l_{t}}{\partial \omega_{t}} \frac{\omega_{t}}{l_{t}}$ is given by:

$$
\epsilon_{l_{t}^{s}}=\frac{1-\epsilon_{u}\left(C_{t+1} / B\right) \frac{\omega_{t} l_{t}}{\omega_{t} l_{t}+\pi_{t}}}{\epsilon_{v}\left(l_{t}\right)+\epsilon_{u}\left(C_{t+1} / B\right) \frac{\omega_{t} l_{t}}{\omega_{t} l_{t}+\pi_{t}}}>0
$$

where $\epsilon_{v}\left(l_{t}\right) \equiv V^{\prime \prime}\left(l_{t}\right) l_{t} / V^{\prime}\left(l_{t}\right) \geq 0$.

In the production sector, each good $i$ is produced by a single firm using capital and labor as inputs and the constant returns to scale technology $y_{t}=A f\left(a_{t}\right) l_{t}$, where $f$ is the intensive production function, $a_{t}=k_{t-1} / l_{t}$ the capital-labor ratio and $A>0$ a scaling parameter. We further assume:

Assumption 2 The intensive production function $f(a)$ is continuous for $a \geq 0$, positively valued and differentiable as many times as needed for $a>0$, with $f^{\prime}(a)>0$ and $f^{\prime \prime}(a)<0$.

Assuming that there is monopolistic competition on the product market, each producer maximizes its profits facing the demand function $d_{t}(i)=$ $\left(p_{t}(i) / P_{t}\right)^{-\frac{\mu}{\mu-1}}\left(I_{t} / P_{t}\right)$, where $I_{t}$ is the aggregate income. It means that the elasticity of the demand of a variety of final good is equal to $\mu /(\mu-1)$ in absolute value and then, the mark-up is $\mu$. At the symmetric equilibrium, we deduce the following expressions for the real wage and the real interest rate:

$$
\begin{gathered}
\omega_{t}=\frac{1}{\mu} A\left[f\left(a_{t}\right)-a_{t} f^{\prime}\left(a_{t}\right)\right] \equiv \omega\left(a_{t}\right) \\
\rho_{t}=\frac{1}{\mu} A f^{\prime}\left(a_{t}\right) \equiv \rho\left(a_{t}\right)
\end{gathered}
$$

Using these two equations, we can easily determine the level of real profits:

$$
\pi_{t}=A f\left(a_{t}\right) l_{t}-\rho_{t} k_{t-1}-\omega_{t} l_{t}=\frac{\mu-1}{\mu} A f\left(a_{t}\right) l_{t}
$$


We can notice that since returns to scale are constant, profits are due to the existence of producer market power and are positively related to the mark-up $\mu$. When $\mu \in(1,+\infty)$ increases (decreases), profits increase (decrease). Furthermore, we obtain the perfectly competitive configuration as a limit case when $\mu$ tends to 1 . Then, the real wage and the real interest rate are respectively equal to the marginal productivities of labor and capital and the monopoly profits $\pi_{t}$ collapse to 0 .

We can now define an intertemporal equilibrium. Substituting equations (9), (10) and (11) into (3) and (6), we obtain:

$$
\begin{gathered}
k_{t}=A\left[f\left(a_{t}\right)-\frac{1}{\mu} a_{t} f^{\prime}\left(a_{t}\right)\right] \frac{k_{t-1}}{a_{t}} \\
U^{\prime}\left[\frac{1}{B} \frac{1}{\mu} A f^{\prime}\left(a_{t+1}\right) k_{t}\right] \frac{1}{\mu^{2}} A^{2} f^{\prime}\left(a_{t+1}\right)\left[f\left(a_{t}\right)-a_{t} f^{\prime}\left(a_{t}\right)\right]=V^{\prime}\left(\frac{k_{t-1}}{a_{t}}\right)
\end{gathered}
$$

These two relations determine the dynamics of the economy and define a two-dimensional dynamic system with one predetermined variable, the capital.

Definition 1 An intertemporal equilibrium with perfect foresight is a sequence $\left(k_{t-1}, a_{t}\right) \in \mathbb{R}_{++}^{2}, t=1,2, \ldots, \infty$, such that (12) and (13) are satisfied.

A steady state of the dynamic system (12)-(13) is a solution $\left(k_{t-1}, a_{t}\right)=$ $(k, a)$ for all $t$, such that:

$$
\begin{gathered}
A\left[\frac{f(a)}{a}-\frac{f^{\prime}(a)}{\mu}\right]=1 \\
U^{\prime}\left[\frac{1}{B} \frac{f^{\prime}(a) a k}{\mu f(a)-a f^{\prime}(a)}\right]=\frac{V^{\prime}(k / a)\left[\mu f(a)-a f^{\prime}(a)\right]^{2}}{f^{\prime}(a)\left[f(a)-a f^{\prime}(a)\right] a^{2}}
\end{gathered}
$$

Following Cazzavillan, Lloyd-Braga and Pintus (1998), we establish the existence of a steady state by choosing appropriately the two scaling parameters $A>0$ and $B>0$ so as to ensure that one steady state coincides with $(k, a)=(1,1)$. From equation $(14)$, we obtain a unique solution:

$$
A^{*}=\frac{\mu}{\mu f(1)-f^{\prime}(1)}
$$

Taken as given $A^{*}$, there is a unique $B^{*}$ defined by: 


$$
U^{\prime}\left[\frac{1}{B^{*}} \frac{f^{\prime}(1)}{\mu f(1)-f^{\prime}(1)}\right]=\frac{V^{\prime}(1)\left[\mu f(1)-f^{\prime}(1)\right]^{2}}{f^{\prime}(1)\left[f(1)-f^{\prime}(1)\right]}
$$

if the following condition is satisfied:

$$
\lim _{x \rightarrow+\infty} U^{\prime}(x)<\frac{V^{\prime}(1)\left[\mu f(1)-f^{\prime}(1)\right]^{2}}{f^{\prime}(1)\left[f(1)-f^{\prime}(1)\right]}<\lim _{x \rightarrow 0} U^{\prime}(x)
$$

Under Assumptions 1 and 2, $A^{*}$ and $B^{*}$ are both strictly positive.

Proposition 1 When condition (18) and Assumptions 1 and 2 are satisfied, $(k, a)=(1,1)$ is a steady state of the dynamic system (12)-(13) if and only if $A$ and $B$ are the unique solutions of (16) and (17).

Before studying the emergence of endogenous fluctuations in the neighborhood of the steady state $(k, a)=(1,1)$, we define $s(a) \equiv f^{\prime}(a) a / f(a) \in(0,1)$ as the elasticity of the intensive production function. Therefore, using equations (9), (10), (11) and $y=A f(a) l$, we can define the labor share, the capital share and the profit share in income as follows:

$$
\frac{\omega l}{y}=\frac{1-s(a)}{\mu}, \frac{\rho k}{y}=\frac{s(a)}{\mu} \text { and } \frac{\pi}{y}=\frac{\mu-1}{\mu}
$$

We can notice that in the limit case of perfect competition $(\mu$ tends to $1)$, the profit share in income tends to 0 , whereas $s(a)(1-s(a))$ represents the capital (labor) share in income.

Finally, we note $\sigma(a)=d \ln a / d \ln (\omega(a) / \rho(a))$ the elasticity of capitallabor substitution. Then, using (9) and (10), we have:

$$
\frac{1}{\sigma(a)}=\frac{d \ln \left(f(a)-a f^{\prime}(a)\right)}{d \ln a}-\frac{d \ln f^{\prime}(a)}{d \ln a}=-\frac{a f(a) f^{\prime \prime}(a)}{f^{\prime}(a)\left(f(a)-a f^{\prime}(a)\right)}
$$

Since $s(a)=f^{\prime}(a) a / f(a)$, we obtain:

$$
\begin{aligned}
& \frac{\omega^{\prime}(a) a}{\omega(a)}=-\frac{a^{2} f^{\prime \prime}(a)}{f(a)-a f^{\prime}(a)}=\frac{s(a)}{\sigma(a)} \\
& \frac{\rho^{\prime}(a) a}{\rho(a)}=\frac{a f^{\prime \prime}(a)}{f^{\prime}(a)}=-\frac{1-s(a)}{\sigma(a)}
\end{aligned}
$$




\section{Indeterminacy and Cycles}

Studying local dynamics, we analyze the emergence of endogenous fluctuations and the influence of imperfect competition on the dynamic properties of the steady state. In order to do that, we first differentiate the dynamic system (12)-(13) in the neighborhood of the steady state $(k, a)=(1,1)$. In what follows, we note $s \equiv s(1)$ and $\sigma \equiv \sigma(1)$. Moreover, $\varepsilon_{v} \equiv V^{\prime \prime}(l) l / V^{\prime}(l)$ and $\varepsilon_{u} \equiv-U^{\prime \prime}(C / B)(C / B) / U^{\prime}(C / B)$ are evaluated at the steady state $(k, a)=$ $(1,1)$. Using expressions $(21)$, one obtains:

$$
\begin{gathered}
\frac{d k_{t}}{k}=\frac{d k_{t-1}}{k}+\frac{(1-s)(s-\sigma \mu)}{(\mu-s) \sigma} \frac{d a_{t}}{a} \\
\frac{d a_{t+1}}{a}=-\frac{\left(\varepsilon_{u}+\varepsilon_{v}\right) \sigma}{\left(1-\varepsilon_{u}\right)(1-s)} \frac{d k_{t-1}}{k}+\left[\frac{s+\varepsilon_{v} \sigma}{\left(1-\varepsilon_{u}\right)(1-s)}-\frac{\varepsilon_{u}(s-\sigma \mu)}{\left(1-\varepsilon_{u}\right)(\mu-s)}\right] \frac{d a_{t}}{a}
\end{gathered}
$$

The trace $T$ and the determinant $D$ of the associated Jacobian matrix, which represent respectively the sum and the product of the two eigenvalues, i.e. the roots of the characteristic polynomial $Q(\lambda) \equiv \lambda^{2}-T \lambda+D=0$, can be written:

$$
\begin{gathered}
T=1+\frac{\left(s+\epsilon_{v} \sigma\right)(\mu-s)-\epsilon_{u}(1-s)(s-\sigma \mu)}{(1-s)\left(1-\epsilon_{u}\right)(\mu-s)} \\
D=\frac{s}{1-s} \frac{\mu-s+\epsilon_{v}[1-s+(\mu-1) \sigma]}{\left(1-\epsilon_{u}\right)(\mu-s)}
\end{gathered}
$$

In what follows, we analyze the characteristic polynomial $Q(\lambda)$, i.e. the trace $T$ and the determinant $D$, to study the local stability of the steady state. We just recall that, as it is well-known, the two eigenvalues have a modulus smaller than one when $Q(1)>0, Q(-1)>0$ and $D<1$. In this case, the steady state is locally indeterminate and sunspot equilibria appear around the steady state. Moreover, when the two eigenvalues are complex conjugates and have a modulus which crosses the value $1(Q(1)>0$, $Q(-1)>0, D=1)$, a Hopf bifurcation occurs, i.e. an invariant closed curve appears around the steady state. In this case, sunspot equilibria occur around the cyclical trajectory if it is locally stable. ${ }^{9}$ We now apply these results to obtain the following proposition:

\footnotetext{
${ }^{9}$ For more details, see Grandmont, Pintus and de Vilder (1998) and Guesnerie and Woodford (1992).
} 
Proposition 2 Assume that $s<1 / 2$ and $\epsilon_{u}<(1-2 s) /(1-s)$, and consider that there exists a steady state $(k, a)=(1,1)$ (Proposition 1). If $0<\sigma<s / \mu$, the steady state is locally indeterminate for $\varepsilon_{v}<\varepsilon_{v_{H}}$ and a Hopf bifurcation occurs for $\varepsilon_{v}=\varepsilon_{v_{H}}$, with:

$$
\varepsilon_{v_{H}}=\frac{(\mu-s)\left[1-2 s-\epsilon_{u}(1-s)\right]}{s[1-s+(\mu-1) \sigma]}
$$

In all other cases, endogenous fluctuations cannot occur.

Proof. Using equations (24) and (25), we first notice that $T>1$ and $D>0$, which ensures that $Q(-1)>0$. Moreover, we have:

$$
Q(1)=\frac{\left(\epsilon_{u}+\epsilon_{v}\right)(s-\sigma \mu)}{\left(1-\epsilon_{u}\right)(\mu-s)}
$$

Hence, $Q(1)>0$ requires $\sigma<s / \mu$. Finally, one notices that $D$ increases with respect to $\varepsilon_{v}$ and $D$ can be smaller than 1 because we assume $s<1 / 2$ and $\epsilon_{u}<(1-2 s) /(1-s)$. In fact under these two assumptions, $D \in(0,1)$ for $\varepsilon_{v}<\varepsilon_{v_{H}}, D=1$ for $\varepsilon_{v}=\varepsilon_{v_{H}}$ and $D>1$ for $\varepsilon_{v}>\varepsilon_{v_{H}}$, where $\varepsilon_{v_{H}}$ is given in the proposition.

This proposition establishes that the emergence of fluctuations due to the volatility of agent expectations and deterministic cycles requires a weak substitution between capital and labor and a not too concave utility function. We now analyze more precisely the influence of imperfect competition on the occurrence of such fluctuations. In this model, the importance of imperfect competition can be measured by the level of the parameter $\mu$ which represents the mark-up. ${ }^{10}$

First, remark that $s / \mu$ decreases from $s$ to 0 when $\mu$ increases from 1 to $+\infty$. Therefore, when market power increases, indeterminacy and endogenous cycles can emerge for a smaller range of elasticities of capital-labor substitution since the upper bound of this range becomes closer to $0 .{ }^{11}$ Moreover, the emergence of endogenous fluctuations requires a weaker substitution between capital and labor than in a perfectly competitive economy. Indeed, in this last case, indeterminacy and cycles can occur if $\sigma<s .{ }^{12}$ Hence, con-

\footnotetext{
${ }^{10}$ When $\mu$ increases, producers have a more important market power. This implies greater levels of mark-up and monopoly profits. Moreover, recall that in the particular case where $\mu$ tends to 1 , market power and monopoly profits disappear. It corresponds to the perfect competition configuration.

${ }^{11}$ This result is quite restrictive since elasticities of capital-labor substitution too close to 0 have not any empirical support. See for example Duffy and Papageorgiou (2000).

${ }^{12}$ One can refer to Reichlin (1986).
} 
cerning capital-labor substitution, imperfect competition does not promote the appearance of endogenous fluctuations, but rather stabilizes the economy.

The level of mark-up also affects the range of labor supply elasticities compatible with indeterminacy. Using (8) and (19), the elasticity of labor supply evaluated at the steady state, that we note $\epsilon_{l^{s}}\left(\epsilon_{v}\right)$, can be written as follows:

$$
\epsilon_{l^{s}}\left(\epsilon_{v}\right)=\frac{1-\epsilon_{u} \frac{1-s}{\mu-s}}{\epsilon_{v}+\epsilon_{u} \frac{1-s}{\mu-s}}
$$

Since indeterminacy occurs for $\epsilon_{v}<\epsilon_{v_{H}}$, the labor supply elasticity has to be greater than $\epsilon_{l^{s}}\left(\epsilon_{v_{H}}\right)$. One can prove that if $\epsilon_{u}$ is sufficiently weak, which means that utility for consumption is not too concave, and the elasticity of capital-labor substitution is smaller than one, this lower bound decreases with respect to the level of mark-up. Considering for simplification the limit case where $\epsilon_{u}=0$, we have:

$$
\epsilon_{l^{s}}\left(\epsilon_{v_{H}}\right)=\frac{1}{\epsilon_{v_{H}}}=\frac{s[1-s+(\mu-1) \sigma]}{(\mu-s)(1-2 s)}
$$

which decreases with respect to $\mu$ when $\sigma<1$. Hence, under imperfect competition, indeterminacy requires a less elastic labor supply than in a perfectly competitive economy, i.e. a condition on labor supply less stringent and opened to criticism. From this point of view, imperfect competition rather promotes endogenous fluctuations.

We now give an intuitive interpretation of the emergence of local indeterminacy in this model. Consider first the case where there is perfect competition ( $\mu$ tends to 1 ) and assume that consumers expect a higher future interest rate. Then, labor supply goes down (see equation (7)). At equilibrium, labor increases and real wage decreases because labor demand is negatively slopped. It has a negative effect on labor income if the elasticity of labor income $\omega l$ with respect to labor is negative $(1-s / \sigma<0)$. In this case, future capital stock decreases (see equation (3)). Hence, future interest rate increases and expectations are self-fulfilling.

Consider now that there is imperfect competition $(\mu>1)$. Following a higher expected interest rate, the increase of labor has the same effect as before on labor income, because the mark-up is constant. However, there is an additional effect due to profit distribution. Indeed, the increase of labor raises monopoly profits. Hence, the future capital stock decreases and the future interest rate increases only if the negative effect of labor income dominates, which requires a smaller elasticity of capital-labor substitution than in the previous case. Consequently, expectations are self-fulfilling for a 
weaker substitution between capital and labor than in a perfectly competitive economy. Furthermore, an increase of the mark-up reinforces the positive effect of profits on next period capital stock. It is why an increase of the level of mark-up reduces the range for indeterminacy of elasticities of capital-labor substitution. Finally, notice that $\frac{d \pi_{t}}{\pi}=(1-s) \frac{d l_{t}}{l}=\frac{(1-s)\left(1-\epsilon_{u}\right)}{\epsilon_{v}} \frac{d \rho_{t+1}}{\rho}$. It means that the greater is $\epsilon_{v}$, the less important is the effect of a variation of the expected interest rate on monopoly profits. This last remark explains why, under imperfect competition, indeterminacy can occur for a less elastic labor supply than in a perfectly competitive economy.

\section{Concluding Remarks}

In this paper, we analyze the stabilizing dynamic properties of imperfect competition. In this way, we introduce monopolistic competition in an overlapping generations model with elastic labor supply and productive capital in order to study the influence of the level of mark-up and monopoly profits on the occurrence of indeterminacy and endogenous fluctuations. We first prove that imperfect competition stabilizes fluctuations because it reduces the range of elasticity of capital-labor substitution compatible with indeterminacy and cycles. However, the conclusion concerning labor supply elasticity goes in the opposite direction. Indeed, under imperfect competition, endogenous fluctuations can also occur under less elastic labor supply.

Showing that imperfect competition reduces the range of technological parameters compatible with the occurrence of endogenous fluctuations, one can then notice that some of our results are not in accordance with Jacobsen (2000) who considers the case of a monetary overlapping generations model. Indeed, he cannot obtain such a conclusion since he does not consider capital accumulation and the unique production factor is labor in his framework.

Finally, this paper suggests that a fiscal policy rule characterized by a balanced budget, a same constant tax rate $\tau \in(0,1)$ on capital and labor incomes and a lump-sum transfer $I_{t}$ affects local dynamics in an overlapping generations economy. Indeed, such a model is similar to the one developed in this paper except that real wage $\omega_{t}$ and real interest rate $\rho_{t}$ are now respectively equal to the productivities of labor and capital and the two budget constraints of consumers become:

$$
\begin{aligned}
& k_{t}=(1-\tau) \omega_{t} l_{t}+I_{t} \\
& C_{t+1}=(1-\tau) \rho_{t+1} k_{t}
\end{aligned}
$$

Moreover, at period $t$, the budget of the government can be written: 


$$
\tau \omega_{t} l_{t}+\tau \rho_{t} k_{t-1}=I_{t}
$$

If one puts $\tau=(\mu-1) / \mu$, one obtains exactly the same model and then identical dynamic properties than in the imperfectly competitive framework analyzed in this paper. Indeed, $1-\tau$ is then identical to the inverse of the mark-up $1 / \mu$ and $I_{t}=\tau y_{t}$ to the monopoly profits $A f\left(a_{t}\right) l_{t}(\mu-1) / \mu$. Consequently, this example shows that, in overlapping generations economies, the introduction of balanced budget rules with constant tax rates and lump-sum transfers modifies local dynamics. This conclusion is clearly different to the one obtained by Guo and Harrison (2004) who show that such a fiscal policy does not have any influence on indeterminacy in the optimal growth model.

\section{Appendix}

In what follows, we explain how we obtain expression (5). In order to determine his consumption of each variety of final good, each consumer maximizes his utility (1) subject to (2) and the two budget constraints that can be rewritten:

$$
P_{t+1} C_{t+1}=r_{t+1}\left(\omega_{t} l_{t}+\pi_{t}\right)
$$

where $P_{t+1}$ is the aggregate price defined in section 2 and $r_{t+1}=P_{t+1} \rho_{t+1}$ is the nominal interest rate. Since $P_{t+1} C_{t+1}$ represents the consumption expenditures of a consumer, it is also equal to $\int_{0}^{1} p_{t+1}(i) c_{t+1}(i) d i$. Then, the problem that the consumer faces can be written:

$$
\begin{gathered}
\operatorname{Max}_{c_{t+1}(i)} B U\left[\left(\int_{0}^{1} c_{t+1}(i)^{1 / \mu} d i\right)^{\mu} / B\right]-V\left(l_{t}\right) \\
\int_{0}^{1} p_{t+1}(i) c_{t+1}(i) d i=r_{t+1}\left(\omega_{t} l_{t}+\pi_{t}\right)
\end{gathered}
$$

From the first order conditions, we obtain:

$$
\left(\frac{c_{t+1}(i)}{c_{t+1}(j)}\right)^{1 / \mu-1}=\frac{p_{t+1}(i)}{p_{t+1}(j)}
$$

After some manipulations, we easily deduce the following expression:

$$
c_{t+1}(i)=\frac{p_{t+1}(i)^{-\mu /(\mu-1)}}{\int_{0}^{1} p_{t+1}(i)^{-1 /(\mu-1)} d i} \int_{0}^{1} p_{t+1}(i) c_{t+1}(i) d i
$$


Using $P_{t+1}=\left(\int_{0}^{1} p_{t+1}^{\frac{1}{1-\mu}}(i) d i\right)^{1-\mu}$ and $\int_{0}^{1} p_{t+1}(i) c_{t+1}(i) d i=P_{t+1} C_{t+1}$, we obtain equation (5).

\section{References}

Benhabib, J., and R. E. A. Farmer (1994), "Indeterminacy and increasing returns," Journal of Economic Theory 63, 19-41.

Benhabib, J., and R. E. A. Farmer (1999), "Indeterminacy and sunspots in macroeconomics," J. B. Taylor, and M. Woodford, eds., Handbook of macroeconomics, 387-448, Amsterdam: North-Holland.

Cazzavillan, G., T. Lloyd-Braga, and P. Pintus (1998), "Multiple steady states and endogenous fluctuations with increasing returns to scale in production," Journal of Economic Theory 80, 60-107.

d'Aspremont, C., R. Dos Santos Ferreira, and L.-A. Gérard-Varet (1995), "Market power, coordination failures and endogenous fluctuations" H. D. Dixon, and N. Rankin, eds., The new macroeconomics: Imperfect markets and policy effectiveness, 94-138, Cambridge: Cambridge University Press.

Dixit, A., and J. Stiglitz (1977), "Monopolistic competition and optimum product diversity," American Economic Review 67, 297-308.

Dos Santos Ferreira, R., and T. Lloyd-Braga (2002), "Can market power sustain endogenous growth in overlapping-generations economies?," Economic Theory 20, 199-205.

Duffy, J., and C. Papageorgiou (2000), "A cross-country empirical investigation of the aggregate production function specification," Journal of Economic Growth 5, 87-120.

Gali, J. (1994), "Monopolistic competition, business cycles, and the composition of aggregate demand," Journal of Economic Theory 63, 73-96.

Grandmont, J.-M. (1985), "On endogenous competitive business cycles," Econometrica 53, 995-1045.

Grandmont, J.-M., P. Pintus, and R. De Vilder (1998), "Capital-labor substitution and competitive nonlinear endogenous business cycles," Journal of Economic Theory 80, 14-59.

Guesnerie, R., and M. Woodford (1992), "Endogenous fluctuations" J.-J. Laffont, ed., Advances in economic theory: Proceedings of the 6th world congress of the econometric society, 289-412, Cambridge: Cambridge University Press. 
Guo, J.-T., and S. G. Harrison (2004), "Balanced-budget rules and macroeconomic (in)stability," Journal of Economic Theory 119, 357-363.

Jacobsen, H. J. (2000), "Endogenous, imperfectly competitive business cycles," European Economic Review 44, 305-336.

Lloyd-Braga, T. (1995), "Increasing returns to scale and endogenous fluctuations," Working paper 65/95, Universidade Catolica Portuguesa.

Reichlin, P. (1986), "Equilibrium cycles in an overlapping generations economy with production," Journal of Economic Theory 40, 89-103.

Seegmuller, T. (2005), "Steady state analysis and endogenous fluctuations in a finance constrained model," Cahiers de la MSE, University Paris 1.

Silvestre, J. (1995), "Market power in macroeconomic models: New developments," Annales d'Economie et de Statistique 37/38, 319-356.

Weder, M. (2000), "Animal spirits, technology shocks and the business cycle," Journal of Economic Dynamics and Control 24, 273-295.

Woodford, M. (1991), "Self-fulfilling expectations and fluctuations in aggregate demand," N. G. Mankiw, and D. Romer, eds., New keynesian economics, 77-110, Cambridge: MIT Press. 